\title{
Role-stress and mental health of government officers of Nepal
}

\author{
Kedar Bahadur Rayamajhi \\ PhD Scholar, Mewar University, Rajasthan, India \\ Email:rkedarnp@yahoo.com
}

\begin{abstract}
S
Stress is the mental phenomenon; caused from the various environmental factors. The main aim of this study is to explore relationship between the role-stress and mental health of government officer working under the different ministries of Nepal. The study was conducted among the 284 government officers comprising level I to III. Standard structured questionnaires were used to measure the role-stress and mental health. The study found that there was no significant difference between position regarding the impact of organizational role stress on their mental and physical health. There was no significant difference found between the class I and III at P = 1.000 followed by class I and II at P=1.000 and class III and class II at $P=1.000$. Data shows that perception of mental and physical health has no different on the basis of their position and job roles. The study observed that there is relationship between the role-stress and mental health. If role stress increased then it negatively effect in mental health. Government employee reported the effect of role stress in their daily life but study has not found the serious effect of role stress in mental health of employees because of their practices of coping mechanism. So, there is need to explore their coping mechanism to manage the stress.
\end{abstract}

\section{KEYWORDS:}

Government officers, Mental health, Nepal, Role stress,

\section{INTRODUCTION}

Stress comes in many forms and affects people of all ages and all walks of life. Modern life is full of hassles, deadlines and demands. In the competitive world, for many people, stress is so common that it has become a way of life. That is why, stress is known as an inevitable evil in modern life. Professionals, such as academicians, administrators, doctors and researchers etc. have always been facing this problem as it directly affects the efficiency of the employee. Stress has become the most important factor influencing individual efficacy and satisfaction in modern day occupational settings. The experience of stress is highly individualized. However, it affects the mental health in general. 
There are no external standards/ indicators that can be applied to predict stress levels in individuals. The degree of stress in our lives is highly dependent upon individual factors such as our physical health, the quality of our interpersonal relationships, attitude towards stress, the number of commitments and responsibilities we carry the degree of others' dependence upon us, expectations, the amount of support, and the number of changes or traumatic events that have recently occurred in our lives.

Employee has to take the role as per their position and function accordingly in the workplace. Each of these positions or roles occupied by an individual is related with job responsibilities or demand standard behavior. These guidelines are developed and given by the organization. The employees understanding and acceptance of these roles determines the level of stress in an individual. Each roles demands specific behavior and failure to exhibit specific behavior leads to problems or conflict. The ensuring stress, i.e., stress due to multiple roles an employee plays in workplace is called role stress. Pareek (1983) developed a psychological tool to measure the stresses in organization known as the Organizational Role Stress Scale which measures the components of role stress

Pareek has defined role as a set of functions, which an individual performs in response to the expectations of others and his or her own expectations about the role. He defined roles as Inter role distance, role stagnation, Role erosion, Role overload, Self- role distance, Role isolation, Role inadequacy, Role ambiguity.

Inter role distance indicates that the same individual has to play multiple roles which may create conflicts between them. When a person works in a same position over a period of time he or she may develop a certain pattern of behavior and then promotion or assuming new role for the person may develop stress is called role stagnation. Role erosion means when a person may feel that some of his/her responsibilities are shifted away and feel underemployed may develop stress is called role erosion. Role overload means when a person is pressed for time or feels that he/she cannot achieve total volume of work expected from him/her. Self- role distance denotes the conflict between the self- concept and expectations from the role. Role isolation means in a role set employee feels that some roles are closer to the employee or some roles are relatively in distant. If linkages are strong feelings of role isolation may be low. Role inadequacy refers to stress experienced when an employee is not given appropriate resources to work. Role ambiguity means when a person is not clear about the various expectations demands from the organization or others or an employee new job begins without sufficient orientation or training.

Grinker (1966) insisted that mental health would depend on an individual's flexibility. Grinker proposed that this involves the ability to adapt a number of different environments in fast-growing and changing world. Mental health is an individual's social and emotional adjustment. Mentally healthy individual is useful for the community and can contribute positively for the community. Healthy are those who have the ability to keep pace with the rapid rate of change. The impaired are out of step, either not keeping up with the pace or 
exceeding it. Hence, it is required to induce a dynamic rate of change of axis in conceptualization of the parameter of mental health and illness. Kumari and Prakash (1986) found the impact of life stress on mental health. A negative correlation ( $r=-0.243)$ was found between life stress and mental health. Role stress and psychological distress relationship was obtained significantly. Neuroticism and occupational and mental strain was also found positively related (Shenoy, 1987). In order to promote mental health psychology focus to such research fields which may denote predisposition to such mentally unhealthy circumstances?

The performance and organizational effectiveness both will go side by side. It has to be seen in the perspective of individual's behavior. Positive attitude and behavior of the organization and at the same time employees' behavior at work and mental health are ultimately affected by overall health of the individual and organization. The relationship between the organization and its individual members are analyzed both in terms of the induced contribution of members and the consequences of the organizational membership for individual health and well-being.

Taber's Cyclopedic Medical Dictionary defines stress as "the result produced when a structure, system or organism is acted upon by forces that disrupt equilibrium or produce strain". The Health and Safety Executive (HSE) defines stress as "the adverse reaction people have to excessive pressures or other types of demand placed on them". It also added that rather than an illness, stress is a condition but if it gets elongated and enlarged, development of mental and physical illness can occur. Stress in organization is often regarded as a 'price of success' or 'a necessary evil of work' (Quick, 1984). Some amount of stress or tension is necessary to motivate the individuals. It is generally believed that excessive, continuous stress is harmful resulting in deterioration in employees adequate, and satisfactory adjustment with various dimensions his /her life. Absenteeism, turnover, poor motivation and job dissatisfaction has already been related with stress (Singh J. , 1995). Stress is inevitable, and so, it is increasingly becoming a focus of variety of empirical investigations due to the human, social and economic costs attached to it (Beehr, 1978; Levi, 1981; Moss, 1981; Ahmad, 1985). Job /role stress has been considered as a person environment misfit. Cooper, C.L, and Marshall J. has noted, "---- by occupational stress is meant negative environmental factors stressors associated with a particular job" (Cooper, 1976). Some researchers have reported occupational stress as disruption in individual's psychological or physiological homeostasis that forces them to deviate from normal functioning in interaction with their jobs and work environment. Caplan found that the effects of divergent job demands become manifest in such forms as job dissatisfaction anxiety, depression and in some cases even serious mental and physiological problems ranging from all the way to coronary heart diseases (Caplan, 1972). Moreover, stress affects not only mental and physical level but also hamper the smooth functioning of the organization (French, 1982; House, 1974). Recently different scientific studies on stress had already been conducted to understand how stress affects performance, workers' satisfaction and their health 
Ivancevich and Matteson found that job stress is directly associated with the role we play or the tasks we have to accomplish in the organization. They include sources of stress associated with role ambiguity, role conflict, quantitative role overload, career development and responsibility for people. Such conditions may interfere with normal or physiological functioning if they perceived as stressful (1980). Some types of stress is considered normal as it may be considered as challenge or positive stress but when stress surpasses the amounts that individuals cannot cope with, both mental and physical changes may occur (Canadian Centre for Occupational Health and Safety, 2000). According to Chatly (2014), stress is a natural part of life and occurs whenever significant changes occur in one's lives which may be positive or negative. It was also mentioned that stress in workplace can be the consequence of conflicts between job demands on the employee and the amount of control an employee has over meeting these demands.

According to Naqvi, Khan, Kant and Khan (2013), insufficient monetary rewards, rigidness in working hours, personal issues, low control over the work environment and bureaucratic management system play a negative role on employees' productivity. Stress is considered to be the cause behind the inclining rate of absence of employers and employees. It was found that absence of financial rewards created more job stress among the public health sector employees. Secondary traumatic stress (STS) has been observed as an occupational hazard of providing direct services to traumatized populations. Hence, social workers involved in direct practice are prone to experience at least some symptoms of STS. Thus, independent of any other traumas that social workers may directly experience, the rate of Posttraumatic Stress Disorder (PTSD) in social workers is twice that of the general population (Bride, 2007). Though the Diagnostic and Statistical Manual of Mental Disorders (DSM IV) does not consider "stress" as a medical diagnosis but it contains a number of recognized psychiatric stress-related conditions such as: Acute stress disorder, Adjustment disorder, Major depressive disorder, Bipolar disorders, General anxiety disorder and post-traumatic stress disorder (Ratelband \& Flanagan, 2003).

According to (Miller \& Major, 2000), stigma may be especially stressful compared to other types of stressors due to its nature of creating unique demands on individuals. For instance, prejudice and discrimination are sources of stress for stigmatized population whereas for nonstigmatized population, it may occur on rare situations only. Kulkarni, Bell, Hartman, \& Herman-Smith (2013), explained, on one hand, working with domestic violence survivors can be highly stressful as it keeps the workers at high risk for burnout and secondary traumatic stress. On the other hand, such work can be meaningful for service providers who take their work as source of satisfaction. From this it can be said that with space of time and experience, workers in this field have been able to cope such a stressful job by the use of different strategies.

Health either physical or mental has been given low priority by the government in Nepal and in the context of mental health it has received even low priority. The individual who is suffering mental disorders could face different type of discrimination and stigmatized by the family and society. A positive attitude towards mental health is thus essential which helps the 
person maintain mental health. This study explores the relationship between the role stress and mental health of government officers of Nepal.

\section{METHODS}

The study is based on the quantitative data collected by using the structured questionnaires developed by Dr. Jagdish Dr. A. K. Srevastava (1983). The test consists of six dimensions of mental health such as: Positive self-evaluation, Perception of reality, Integration of personality, Autonomy, Group oriented attitudes and Environmental mastery. The crosssectional data was collected to test the hypothesis. The sample of the present investigation comprised of 284 Nepal government employees belonging to section officer level to especial class (Secretary) levels, randomly selected from various Ministries and departments of government of Nepal. The study was conducted in 2013 in Kathmandu valley. The developed questionnaire was ensuring the reliability and validity of instrument by test-retest method. Data was analyzed by using the SPSS (data analysis software). The statistical tools; descriptive analysis, ANOVA and multiple comparisons were done to present the data.

\section{RESULTS \& DISCUSSIONS}

"Workplace stress" is the harmful physical and emotional responses that can happen when there is a conflict between job demands on the employee and the amount of control an employee has over meeting these demands. In general, the combination of high demands in a job and a low amount of control over the situation can lead to stress (Chandraiah \& Rao, 2012). Stress effect (affects) the mental and physical health of people. Basically, mental health determined the level of job satisfaction and work performances of employees. Healthy environment can lead the better performances with high level of job satisfaction. A study was conducted to assess the impact of job stress on employee job satisfaction. 134 employees from telecom sector of Pakistan were taken for the study. It revealed that stress played a negative role on employee's job satisfaction. For this study, job stress was measured by using stressors such as workload, conflict at work and physical environment (Mansoor, Fida, Nasir, \& Ahmad, 2011). Similar report was identified by the other previous study also which revealed negative relationship between job stress and job satisfaction among academic staff in Malaysia. Role conflict, Relationship with others, Workload Pressure, Home-work Interface, Role ambiguity and Performance pressure were taken as job stressors. Motivation was found to be important factor affecting job stress among employees. It was claimed that negative job stress among the people responsible for assisting the future generation's education will ultimately affect their intellectual and social abilities (Ahsan, Abdullah, Fie, \& Alam, 2009).

1. Correlation between the occupational role stress and mental health inventory Table 1: Correlation between the occupational role stress and mental health inventory 


\begin{tabular}{|l|l|l|}
\hline Occupational Role stress & 1 & $0.005 * *$ \\
\hline Mental health inventory & -0.167 & \\
\hline$* *$ Correlation is significant at the 0.01 level (2-tailed). & & \\
\hline
\end{tabular}

Data source: Field survey, 2013

There was significant relationship found between the job-stress and mental health of government officers at the $\mathrm{P}=0.005$ level of significance. The findings of this study found similar with the findings of previous study. The mental health is negatively and significantly correlated with occupational stress. As the finding of Jakkula V. Rao and K. Chandraiah, there was negative correlation found between the mental health and occupational stress (Rao \& Chandraiah, 2012).

The findings of this study accepted the hypothesis that there was significant relationship between the job-stress and mental health of government officers.

Negative effect in mental health of employees can be observed from their day to day work performances; their punctuality, involvement, interaction, reporting ...etc. it is said that the workplace which is extremely stressed leads to absenteeism, lack of involvement, lack of participation in decision making, apathy and indifference, lack of creativity or motivation (Workplace Stress - General, 2008). A previous study assessed the relationship between job satisfaction and job stress work outcomes, such as intention to leave the employer and organizational citizenship behavior (OCB). Stressful work and OCB were found to have no relationship at all but stressful work was found to increase the desire to leave the job. Satisfaction on job had a positive relationship with OCB but it played a strong negative role on employees' intention to leave. It was revealed that employee who is satisfied with his/her job can easily cope with his/her stressful work due to the environment provided at his/her working environment (Paillé, 2011). Stress can have both positive and negative effect; positive effect can be motivating whereas negative effect can lead to different physical and psychological problems through distress, rejection and depression (Mehta \& Singh, 2014).It was revealed that $36 \%$ Nepalese nurses cited lack of opportunity to discuss problems with peers as a low source of stress whereas 30\% cited inadequate emotional preparation, $24 \%$ cited sexual harassment,20\% cited discrimination because of race or ethnicity and $10 \%$ cited gender based discrimination (Ahsan, Abdullah, Fie, \& Alam, 2009).

\section{Impact of Stress in mental and physical health in total}

Impact of organizational roles stress in mental and physical health was measured among the respondents. There was 20 questions asked to respondents covering their mental and physical health like; pain in heart and chest, severe headache, dizziness, afraid, depressed, worrying, irritation and so on.

Table 2: Impact of Stress in mental and physical health in total

\begin{tabular}{|l|l|l|l|l|l|}
\hline & Sum of Squares & Df & Mean Square & F & Sig. \\
\hline Between Groups & .386 & 2 & .193 & & \\
Within Groups & 139.600 & 281 & .497 & .388 & .679 \\
\hline Total & 139.986 & 283 & & & \\
\hline
\end{tabular}


Data source: Field survey, 2013

The overall impact of stress was measured by using the F-test. There was no significant difference $(\mathrm{F}=.388$ at $\mathrm{P}=.679)$ found on impact of stress among the respondents. As the finding showed that, there is no severe impact of stress seen in mental health of government officers at all level. The finding explains that Nepalese employees are not taking stress factors very seriously. The reasons may be many. Nepalese work culture seems to be less stress prone because time value at workplace is negative. For many positions Government of Nepal has not yet developed the job description as well as job specification to measure the performance. At workplace employee are very much inclined to the political link or keep relation with union rather than focusing on performance for the promotion or career opportunity. As mentioned earlier, group value or collectivistic value prevails and they share their difficulties among each other and feel low stress even everyday life. Nepalese society looks smiling society and very often people take the stress lightly and adjust easily. So, Nepalese personality indicates stress resistant and highly adjectives in its nature.

Stress plays a negative role on individuals' personal and professional lives (McNeill \& Jordan, 1993).Workplace stress has been proved to have awful impact on the health and well-being of employees as well as on the productivity and prosperity of the workplace (Melanie Bickford, 2005). According to the report, the illnesses linked with prolonged exposure to stress encompass coronary heart disease, hypertension, some types of cancer, Rheumatoid arthritis, Diabetes mellitus, Irritable bowel syndrome, Depression, Anxiety,Ulcerative colitis,Strokes,Stomach and duodenal ulcers, the bacterium Helicobacter pylori, Indigestion and heartburn and Chronic fatigue syndrome.

\section{Multiple Comparisons of positions regarding the impact of organizational role stress on their mental and physical health}

There was no significant difference found between position regarding the impact of organizational role stress on their mental and physical health. There was no significant difference found between the class I and III at $\mathrm{P}=1.000$ followed by class I and II at $\mathrm{P}=$ 1.000 and class III and class II at $\mathrm{P}=1.000$. Data shows that perception of mental and physical health has no different on the basis of their position and job roles.

Table 3: Multiple comparisons of positions and mental health

\begin{tabular}{|l|l|l|l|l|}
\hline (I) Position & (J) Position & Mean Difference (I-J) & Std. Error & Sig. \\
\hline \multirow{2}{*}{ Class I } & Class III & .06629 & .11428 & 1.000 \\
\cline { 2 - 5 } & Class II & .11333 & .12869 & 1.000 \\
\hline \multirow{2}{*}{ Class III } & Class II & .04704 & .09873 & 1.000 \\
\hline
\end{tabular}

Data source: Field survey, 2013

Finding of a previous study reveals that the two groups differed significantly on state of mind ( $\mathrm{t}=2.26$ significant at 0.01 level). But these two groups did not differ on resilience and confidence level ( $\mathrm{t}=1.26$ and 1.66 not significant at 0.05 level respectively). The senior managers are experiencing better mental health than the junior managers (mean values 18.77 and 17.28) respectively (Rao \& Chandraiah, 2012). 
Job stressors have been correlated to poor job performance and lead to feelings of being under substantial time pressure as well as depression (Parker, 1983).Mounting stress can create stressors, which can lead to job burnout. The American Institute of Stress (2006) reported that stress oriented accidents, absenteeism, employee turnover, reduced productivity, medical and insurance costs and workers' compensation costs U.S. businesses between $\$ 200$ and $\$ 300$ billion each year (As cited in Reinardy, 2012). Both stress and burnout are felt by clinicians and staffs in health care organizations also due to their job and unique pressures of the medical field. But the result of stress and burnout does not only affect the health and wellbeing of employees but for the patients through poor quality care (Hayashi, Selia, \& MDonnell, 2009). There is multiple effect of stress in individual, family and social life. It is also found that those parents who bring stress at home from their jobs can introduce stress into children's lives (Heinrich, 2014).

\section{Dimension of Mental Health}

It has been well established that stress or distress results from various types of psychological or psychosomatic problems in an individual. Biologists use the term coping to refer to the adjustment of a tissue system or the body to noxious agents as in the Selye's (1956) "General Adaptation Syndrome". However, coping has long been described as a central role in human adaptation. Coping is primarily a psychological concept. The coping process, in broadest sense, refers to any attempt to deal with stressful situation when a person feels she/he must do something about it. A variety of coping strategies have been suggested by psychologists or behavior researchers. It ranges from simple to complicated skills and techniques. Lazarus (1981) described four basic modes of coping: "Instrumental" coping strategies or direct action; Intra-psychic strategies, Inhibition of action and Information seeking. Latack, J. C suggested three categories of coping strategies such as, action coping, cognitive reappraisal, and symptom management (Latack J. C., 1984; Latack J. , 1986). Similarly, Wilder and Pluchik (1982) suggested eight types of coping responses, namely: suppression, help seeking, and replacement, blaming others or the system, substitution, mapping, and reversal. Carver, C.S; Weintraub, J.k; Scheer, M.F suggested fourteen coping strategies. However, people normally combine the levels of operations and orientation and some time, combine two operational lives or two modes of efforts to cope with stressful situation.

Table 4: Dimensions of mental health

\begin{tabular}{|c|c|c|c|c|c|c|c|c|c|}
\hline $\begin{array}{l}\text { Dimension of } \\
\text { Mental Health }\end{array}$ & Response & $\sum_{\bar{E}}^{n}$ & 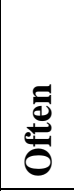 & : & :ँ̀ & 曋 & 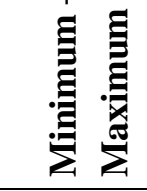 & 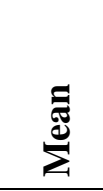 & \\
\hline \multirow{2}{*}{\begin{tabular}{|l} 
Positive Self \\
Evaluation
\end{tabular}} & Frequency & & 2 & 277 & 5 & 284 & \multirow{2}{*}{$2-4$} & \multirow{2}{*}{$\begin{array}{l}3.010 \\
6\end{array}$} & \multirow{2}{*}{.15692} \\
\hline & Percent & & 0.7 & 97.5 & 1.8 & 100 & & & \\
\hline \multirow{2}{*}{$\begin{array}{l}\text { Group } \\
\text { Oriented } \\
\text { Attitude }\end{array}$} & Frequency & & & 217 & 67 & 284 & \multirow[b]{2}{*}{$3-4$} & \multirow{2}{*}{$\begin{array}{l}3.235 \\
9\end{array}$} & \multirow[b]{2}{*}{.42532} \\
\hline & Percent & & & 76.4 & 23.6 & 100 & & & \\
\hline Environmental & Frequency & & 1 & 278 & 5 & 284 & $2-4$ & 3.014 & .14492 \\
\hline
\end{tabular}




\begin{tabular}{|c|c|c|c|c|c|c|c|c|}
\hline Mastery & Percent & 0.4 & 97.9 & 1.8 & 100 & & 1 & \\
\hline \multirow{2}{*}{$\begin{array}{l}\text { Perception of } \\
\text { Reality }\end{array}$} & Frequency & 7 & 272 & 5 & 284 & \multirow{2}{*}{$2-4$} & 2.993 & \multirow{2}{*}{.20580} \\
\hline & Percent & 2.5 & 95.8 & 1.8 & 100 & & 0 & \\
\hline \multirow{2}{*}{$\begin{array}{l}\text { Integration of } \\
\text { Personality }\end{array}$} & Frequency & 5 & 276 & 3 & 284 & \multirow{2}{*}{$2-4$} & 2.993 & \multirow{2}{*}{.16798} \\
\hline & Percent & 1.8 & 97.2 & 1.1 & 100 & & 0 & \\
\hline \multirow{2}{*}{ Autonomy } & Frequency & 17 & 250 & 17 & 284 & \multirow{2}{*}{$2-4$} & 3.000 & \multirow{2}{*}{.34661} \\
\hline & Percent & 6.0 & 88.0 & 6.0 & 100 & & 0 & \\
\hline
\end{tabular}

Data Source: Field Survey, 2013

Table 4 shows that in Positive Self Evaluation strategy, percentage varies from $0.7 \%$ often, $97.5 \%$ rarely and $1.8 \%$ never reported respectively. The average mean score is 3.0.

The data indicates that regarding Positive Self Evaluation strategy, Nepalese style of stress management seems unplanned and behavior reactive. This data raised serious questions of negative work culture as well as irresponsibility towards self and other.

Positive Self Evaluation is one of the way through which one can manage stress effectively and enhance the performance. Several studies showed the evidence that those who possess Positive Self Evaluation lead satisfactory and happy life. Therefore, Nepalese administrative work culture need to pay attention seriously to adopt Positive Self Evaluation strategy for better life and performance.

In Group Oriented Attitude strategy, the respondents expressed that 76.4 falls under rarely category and $23.6 \%$ under for never. The average mean score is found 3.23. Nepalese society seems to be traditional and group oriented but the data reveals that it is not so. The reason behind it may be the modernization of the society. People are becoming more and more individualistic and have to face fierce competition. Urbanization and development of IT service reduce the environment for the people to talk in group and organization is also pressing for high productivity in a given time. Hence, it is now time to create team or group in the organization to achieve the organizational goal and make people happy.

Regarding the strategy- Environmental Mastery, $0.4 \%$ of the respondents reported often, $97.9 \%$ rarely and $1.8 \%$ never. The average mean score is 3.0 for this strategy. For the strategy- Perception of Reality-, the percentage varies from $2.5 \%$, to $95.8 \%$ and $1.8 \%$. The average mean score is 2.99 . Respondents expressed the similar types of responses as in other strategy. When analyzed the data, it can be said that government employees are not very serious to manage stress. They have developed high level of immunity power towards stress. Their outlook towards other and world seems to be mean and self-centered. It is now time to improve their awareness towards stress management and develop skills; otherwise it may be too late when employees feel more mental disorders and other behavioral problems.

Regarding Integration of Personality strategy, 1.8\% employees said often, $97.2 \%$ said rarely and $1.1 \%$ said never. The average mean score is 2.99 . It indicates the balance of psychic forces in the individual and includes the ability to understand and share other people's emotions. But Nepalese bureaucrats have shown less concern with the factors which are vital 
to balance life in many facets. Thus, regarding mental health issue, they are less aware and concerned and pay less attention towards it. Now time has come to think and rethink on employees' mental health; and their perception has to be changed for the benefit of individual and organization.

Autonomy includes standards for one's actions, dependence of development upon own potentialities rather than dependence on other people. For this item, out of total respondent, $6 \%$ reported often, $88 \%$ reported rarely and $6 \%$ said never, whereas mean score of this strategy is 3. More or less, the respondents gave same type of answers. The reason is clear that even the educated employees give less attention and priority to the stress coping mechanism. They use stress coping strategy as the context and the situation demands.

\section{Regression analysis between the role stress and mental health}

Multiple regression tells how much of the variance in the dependent variable can be explained by the independent variable. From the model summary indicated in Table 26, we can see that the $\mathrm{R}^{2}$ value is .087 which means that independent variable only explains $8.7 \%$ of the variation in the dependent variable. The adjusted $\mathrm{R}^{2}$ value is .060 which means that the dimensions of occupational role stress contributed only $6 \%$ of mental health inventory. The remaining $94 \%$ were contributed by other factors not included in this study.

Table 5: Regression Analysis of Role stress and Mental Health

\begin{tabular}{|c|c|c|c|c|c|c|c|}
\hline \multicolumn{8}{|c|}{ Model Summary } \\
\hline Model & \multicolumn{2}{|l|}{$\mathrm{R}$} & R Square & \multicolumn{2}{|c|}{ Adjusted R Square } & \multicolumn{2}{|c|}{$\begin{array}{l}\text { Std. Error of the } \\
\text { Estimate }\end{array}$} \\
\hline \begin{tabular}{l|l}
1 & $.294^{\mathrm{a}}$ \\
a. Predictors: (Constant), R
\end{tabular} & \multicolumn{2}{|l|}{$.294^{\mathrm{a}}$} & .087 & \multicolumn{2}{|l|}{.060} & \multicolumn{2}{|l|}{5.564} \\
\hline \multicolumn{8}{|c|}{ Role Stagon, Self-Role Distance, Role Isolation, Inter-Role Distance } \\
\hline \multicolumn{8}{|c|}{ ANOVA $^{\mathbf{a}}$} \\
\hline \multicolumn{2}{|c|}{ Model } & \multicolumn{2}{|c|}{ Sum of Squares } & Df & Mean Square & $\mathrm{F}$ & Sig. \\
\hline \multirow{3}{*}{1} & Regression & 807 & .721 & 8 & 100.965 & 3.261 & $.001^{\mathrm{b}}$ \\
\hline & Residual & 851 & 4.008 & 275 & 30.960 & & \\
\hline & Total & 932 & 1.729 & 283 & & & \\
\hline \multicolumn{8}{|c|}{ a. Dependent Variable: Mental health inventory } \\
\hline \multicolumn{8}{|c|}{$\begin{array}{l}\text { b. Predictors: (Constant), Role inadequacy, Role overload, Role Erosion, Role Ambiguity, } \\
\text { Role Stagon, Self-Role Distance, Role Isolation, Inter-Role Distance }\end{array}$} \\
\hline \multicolumn{8}{|c|}{ Coefficients } \\
\hline \multirow[t]{2}{*}{ Mode } & & & \multicolumn{2}{|c|}{$\begin{array}{l}\text { Unstandardized } \\
\text { Coefficients }\end{array}$} & \multirow{2}{*}{$\begin{array}{l}\text { Standardized } \\
\text { Coefficients }\end{array}$} & \multirow[t]{2}{*}{$\mathrm{t}$} & \multirow[t]{2}{*}{ Sig. } \\
\hline & & & $\mathrm{B}$ & Std. Error & & & \\
\hline \multirow{3}{*}{1} & (Constant) & & 152.138 & 1.918 & & 79.304 & .000 \\
\hline & Self-Role Dis & ince & .237 & .135 & .129 & 1.757 & .080 \\
\hline & $\begin{array}{l}\text { Inter-Role } \\
\text { Distance }\end{array}$ & & -.266 & .113 & -.179 & -2.359 & .019 \\
\hline
\end{tabular}




\begin{tabular}{|l|l|l|l|l|l|l|}
\hline \multirow{8}{*}{} & Role Stagnation & -.276 & .134 & -.149 & -2.061 & .040 \\
\cline { 2 - 7 } & Role Ambiguity & -.345 & .116 & -.205 & -2.983 & .003 \\
\cline { 2 - 7 } & Role overload & .172 & .116 & .113 & 1.480 & .140 \\
\cline { 2 - 7 } & Role Isolation & .071 & .128 & .042 & .557 & .578 \\
\cline { 2 - 7 } & Role Erosion & .053 & .124 & .031 & .424 & .672 \\
\cline { 2 - 7 } & Role inadequacy & -.076 & .127 & -.044 & -.599 & .550 \\
\hline a. Dependent Variable: Mental health inventory
\end{tabular}

Data source: Field survey, 2013

The regression analysis on all eight dimensions of occupational role stress were significant at $\mathrm{p} \leq 0.05$ (.001), at $\mathrm{F}=3.261$. However, it was found out that only three dimensions were significant which have $\mathrm{p}$-value $\leq 0.05$, namely inter-role distance, role stagnation and role ambiguity. Another five dimensions i.e. Self-role distance, role overload, role isolation, role erosion and role inadequacy were not significant to mental health inventory since the p-value of each was $0.08, .140, .578, .672$ and 0.550 . We may conclude by saying that at least 3 dimensions of occupational role stress, namely inter-role distance, role stagnation and role ambiguity has impact on mental health inventory.

In connection with findings of my study, a study conducted by Jasmanibinti Mohd Yunus and Abdul Jumaat bin Mahajar among 329 administrative and diplomatic (PTD) officers in Putrajaya and Kuala Lumpur of Malaysia found that the regression analysis on all six dimensions of occupational stress were significant at $\mathrm{p}<0.05$, at $\mathrm{F}=19.381$. However, it was found out that only four dimensions were significant which have $\mathrm{p}$-value $<0.05$, namely role overload, role ambiguity, role boundary and role insufficiency. Another two dimensions, i.e. role responsibility and physical environment were not significant to psychological well-being since the p-value of each was 0.475 , and 0.976 . We may conclude by saying that at least 4 dimensions of occupational stress, namely role overload, role ambiguity, role boundary and role insufficiency has impact on psychological well-being (Mahajar \& bin, 2011). In study of Mahajar, there is only two dimensions namely role overload and role ambiguity are found similar with my study. Regarding these two dimensions, both dimensions was found significant to psychological well-being in his study but in my study only role ambiguity was found significant to the mental health inventory.

There is need of coping strategies to overcome the stress among the working people. Coping strategies like avoidance, transference, problem solving and optimism were found to be used by nursing students to cope up stress (Singh, Sharma, \& Sharma, 2011). According to Roberts \& Timmons (2004), the most effective way for reducing job stress is eradicating the causes of stress in the workplace. It was found that union growth can reduce job stress by providing workers the voice to cope effectively with job hazards. Sax (1996) revealed that $61 \%$ of faculty mentioned that the negative activities of students become a major source of stress (As cited in Gates, 2000). According to Iqbal \& Kokash (2011) in case of university, the department of management and administration should also concentrate on stress of faculty basically on two sectors which are: Student Interactions and Professional Identity in order to 
reduce the stress among faculty members. Every single member of the faculty should be provided such an environment that he/she should cordially feel themselves being a part of the institution.

\section{CONCLUSION}

The study found the relationship between role stresses and mental health of employees. Excess stress can manifest itself in a variety of emotional, behavioral, cognitive and even physical symptoms. Common somatic (physical) symptoms often reported by those experiencing excess stress include sleep disturbances, muscle tension, headache, gastrointestinal disturbances, and fatigue. Psychological symptoms that can accompany excess stress include depression, anxiety, loss of enthusiasm or energy, and mood disorders etc. Employees' stress at work, effectiveness of the organization and mental health of employees are determined by a number of environmental and personal characteristics. Among others the nature of the organizations (governmental and non-governmental) is a predominant variable, which, determines the job, the degree of employees' job stress and organizational effectiveness, and eventually affects the mental health of the employees. The present research examined the relationship among employees' perceived role stress and mental health of the employees. The study also compared four-tire role, values, coping strategies (technical and non-technical officers of Government of Nepal) and mental health with regard to these variables and also relationship among them. The respondents did not report any serious effect of role stress on their mental health; but felt some effect in their daily life. It was found that the common practices of coping mechanism; sharing with family and friends, taking leave, going in long journey, doing some physical exercise were practiced by employees to relax from the stress. Further study can do to identify the effective coping mechanism to reduce the stress comparing the employee of private and public sector.

\section{Bibliography}

Ahmad, S. B. (1985). A Study of Stress among executives. Journal of Personality \& clinical studies, l(2), 47-50.

Ahsan, N., Abdullah, Z., Fie, D. Y., \& Alam, S. S. (2009). A Study of Job Stress on Job Satisfaction among University Staff in Malaysia: Empirical Study. European Journal of Social Sciences, $8(1), 121-131$.

As cited in Gates, G. S. (2000). Teaching -Related Stress:The Emotional Management of Faculty. The Review of Higher Education, 23(4), 470.

As cited in Reinardy, S. (2012). TV Sportcasters1,Burnout 0:Resources Sideline the Job Stressors of Sports Broadcasters. Journal of Sports Media, 7(1), 89-107.

Beehr, T. a. (1978). Job stress, employee health and organizational effectiveness: A facet analysis, model and literature review. Personnel Psychology, 31, 665 - 699.

Bride, B. E. (2007, January). Prevalence of Secondary Traumatic Stress Among Social Workers.

Social Work, 52(1), 63-70. 
Canadian Centre for Occupational Health and Safety. (2000).

Caplan, R. (1972). Organizational Stress and Individual Strain: A social psychological study of risk factors in coronary heart disease among administrators, engineers and scientists. University of Michigan.

Chandraiah, K., \& Rao, J. V. (2012, Jan-Apr). Occupational stress, mental health and coping among information technology professionals. Indian Journal of Occupational and Environmental Medicine, 16(1), 22-26.

Cooper, C. a. (1976). Occupational sources of stress. A review of the literature relating to coronary heart disease and mental ill health. Journal of occupational Psychology, 49(1), 11-28.

French, J. C. (1982). The mechanisms of job stress and strain. John Wiley.

Grinker, R. (1966). Normality, theoretical and clinical concept of mental health. In M. Offer D. and Sabshine. New York.

Hayashi, A., Selia, E., \& MDonnell, K. (2009, August). Stress and Provider Retention in Undeserved Communities. Journal of Health Care for the poor and undeserved, 20(3), 597-604.

Heinrich, C. J. (2014). Parent's Employment and Children's wellbeing. The Future of Children, 24(1), 121.

House, J. (1974). Occuptional Stress and Coronary heart disease: A review and theoretical integration. Journal of health and Social Behaviors, 15, 12-27.

Iqbal, A., \& Kokash, H. (2011, August). Faculty Perception of Stress and Coping Strategies in a Saudi Private University: An Exploratory Study. International Education Studies, 4(3), 138-149.

Ivancevich, J., \& Matteson, M. (1980). Stress and work. Glenview,III: scott, Foresman and Company.

Kulkarni, S., Bell, H., Hartman, J. L., \& Herman-Smith, R. L. (2013, June ). Exploring Individual and Organizational Factors Contributing to Compassion Satisfaction, Secondary Traumatic Stress, and Burnout in Domestic Violence Service Providers. Journal of the Society for Social Work and Research , 4(2), 114-130.

Kumari, R. H., \& Prakash, I. J. (1986). Life stress and mental health: A study age and sex differences. Journal of Personality and Clinical Studies, 2, 103-107.

Latack, J. (1986). Coping with job stress:Measures and future directions for scale development. Journal of Applied Psychology, 377-85.

Latack, J. C. (1984). Career transition within organizations: An exploratory study of work, non-work and coping strategies. Organizational Behavior and Human Performance, 34, 296-322.

Lazarus, R. (1981). The stress and coping paradigm. In D. In C. Eisdofer, \& C. \&. Kteiuwan, Models for Clinical Pathlogy (Eds.). New York: Spectrum Medical and Scientific Book.

Levi, L. (1981). Preventing work stress. Reading mass: Wesley. 
Mahajar, J. b., \& bin, A. J. (2011, December). Stress and Psychological well-Being of Government officers in Malaysia. The Journal of Human Resource nd Adult Learning, Vol. 7(Num 2).

Mansoor, M., Fida, S., Nasir, S., \& Ahmad, Z. (2011). The Impact of Job Stress on Employee Job Satisfaction A Study on Telecommunication Sector of Pakistan. Journal of Business Studies Quarterly, 2(3), 50-56.

McNeill, J. H., \& Jordan, L. J. (1993). Factors that contribute to Stress as Reported by Teachesr of Deaf Students at Residential Schools. American Annals of the Deaf, 138(3), 284-287.

Mehta, R., \& Singh, I. (2014). STRESS AMONG NURSES WORKING IN CRITICAL CARE AREAS AT A TERTIARY CARE TEACHING HOSPITAL NEPAL. Journal of Chitwan Medical College, 4(10), 42-48.

Melanie Bickford . (2005).

Stress in the Workplace: A General Overview of the Causes, the Effects, and the Solutions . Canadian Mental Health Association;Newfoundland and Labrador Division .

Miller, C., \& Major, B. (2000). Coping with Stigma and Prejudice. In T.F.Heatherton, R. Kleck, M. Hebi, \& J. Hull, The social psychology of stigma (pp. 243-272). New York:Guilford.

Moss, R. (1981). Work Environment Scale Manual Palo Alto. CA: Consulting Psychology Press.

Naqvi, H. M., Khan, A. M., Kant, Q., \& Khan, N. S. (2013). Job Stress and Employees ${ }^{\text {ee }}$ Productivity, Case of Azad Kashmir, Public Health Sector. Interdisciplinary Journal of Contemporary Research in Business, 5(3), 526-542.

Paillé, P. (2011). Stressful Work, Citizenship Behaviour and Intention to Leave the Organization in a High Turnover Environment: Examining the Mediating Role of Job Satisfaction. Journal of Management Research, 3(1).

Parker, D. \&. (1983). Organizational determinants of hob stress. Organizational Behavior and Human Performance, 32 , 160-177.

Quick, J. \&. (1984). Preventive Stress Management at Organizational level. Personnel, 63, 24-34.

Rao, J. V., \& Chandraiah, K. (2012, Jan-Apr). Occupational stress, mental health and coping among information technology professionals. Indian Journal of Occupational and Environmental Medicine, 16(1), 22-26.

Ratelband, B., \& Flanagan, J. (2003, November 14). Managing Stress-Related Claims. Retrieved March 2, 2015, from http://www.mccarthy.ca/pubs/Stress_Claims.pdf

Selye, H. (1956). The stress of life. New York: McGraw Hill.

Shenoy, J. (1987). Stressfulness of daily role, personality and mental health of women. Banglore: Banglore University.

Singh, C., Sharma, S., \& Sharma, R. K. (2011, October). Level of stress and coping strategies used by nursing interns. Nursing and Midwifery Research Journal, 7(4), 152-160. 
ISSN: 2362-1303 (Paper) | elSSN: 2362-1311(Online)

Singh, J. (1995). A Comparative Study of job stress, coping and mental, Health of Nepali and Indian Bank Employees. Ph.D. Thesis, BHU. India.

Wilder, J., \& Plutchik, R. (1982). Preparing the professional: Building prevention into training. In W. (. Paine, Job Stress and Burnout: Research, Theory, and InterventionPerspectives (pp. 113129). London: Sage Publication.

Workplace Stress - General. (2008). Retrieved May 4, 2015, from http://www.ccohs.ca/oshanswers/psychosocial/stress.html 